\title{
Exploring Critical Success Factors Affecting E- Learning to High Schools' Students in Kuwait
}

\author{
Fatima Al-Qaoud ${ }^{1,2}$, Andrew Carruthers ${ }^{2}$, Mumtaz Kamala ${ }^{2}$, SamiHabib $^{1}$ and Raed Abd- \\ Alhameed ${ }^{2}$

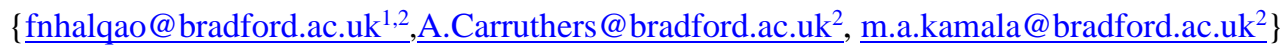 \\ ${ }^{1}$ Kuwait University, Block 4, Al-khaldiya, Kuwait. \\ ${ }^{2}$ Faculty of Engineering and Informatics, University of Bradford, Bradford, BD7 1DP, UK.
}

\begin{abstract}
Recently, many institutions are seeking to identify critical success factors (CSFs) that affect ELearning among their students in different educational systems. Critical success factors are activities and tasks that must be accomplished to satisfy ultimate success in a specific area. Exploring CSFs of students will assist students to achieve successful results based on their understanding and comprehension. Teachers are responsible for delivering information to students professionally; thus, they have to emphasize their strengths and promote them as well as addressing their weaknesses. This paper presents investigations and explorations of critical success factors (CSFs) that positively affect high school students in Kuwait to increase their creativity and innovation. This requires taking into consideration cultural, geographical and social aspects. Exploring critical success factors will contribute to attaining higher results of students' excellence and superiority, and will lead to the enhancement of high school students' learning and understanding of different subjects.
\end{abstract}

Keywords: Critical success factors, E-learning, educational system, technology, and high school, Blending Learning (BL).

\section{Introduction}

Continuous development of education requires tracking the latest orientations of pedagogical tools and instruments. Critical success factors CSFs are the most notable features of educational evolution. Researchers have proposed many definitions of CSFs. For instance, critical success factors can be defined as 'the critical area in which an organization or the individual must accomplish in order to achieve its mission' [2-1]. The term critical success factor appeared in researches since the 80s [3], to find out reasons behind the success of some organizations compared with others. Critical success factors are activities and components that have to be implemented to assure competitive progress among individuals and organizations [4].

Many researchers have discussed the most effective CSFs, and they proposed hypotheses, frameworks, and models to predict the appropriate ones to support blended learning (BL). They found many factors that could not be standardized for a specific institution because some aspects of the factors were variable dependent on region, culture, society, etc. There are six dimensions of CSFs to use in Mobile Learning (M-Learning), which are learners' characteristics; instructors' characteristics; system quality and mobile learning environment; institution and service quality; 
course and information quality, and Motivation [5]. The study found that those dimensions were significant predictors for learners' behavioural intention to use Mobile Learning.

This work will explore CSFs of high schools' students in Kuwait to increase their creativity and innovation and to emphasize students' strengths to be more inventive in different fields and to eliminate those weaknesses that would impede their success.

\section{Classifications of Critical Success Factors}

Previous studies discussed the CSFs in the context of several countries that support BL for students in the present digital era. Critical factors that affect the behavioural intention of students to use Mobile Learning (M-Learning), have been classified into six dimensions as shown in Figure 1 [5] and each dimension is affected by several success factors [5].

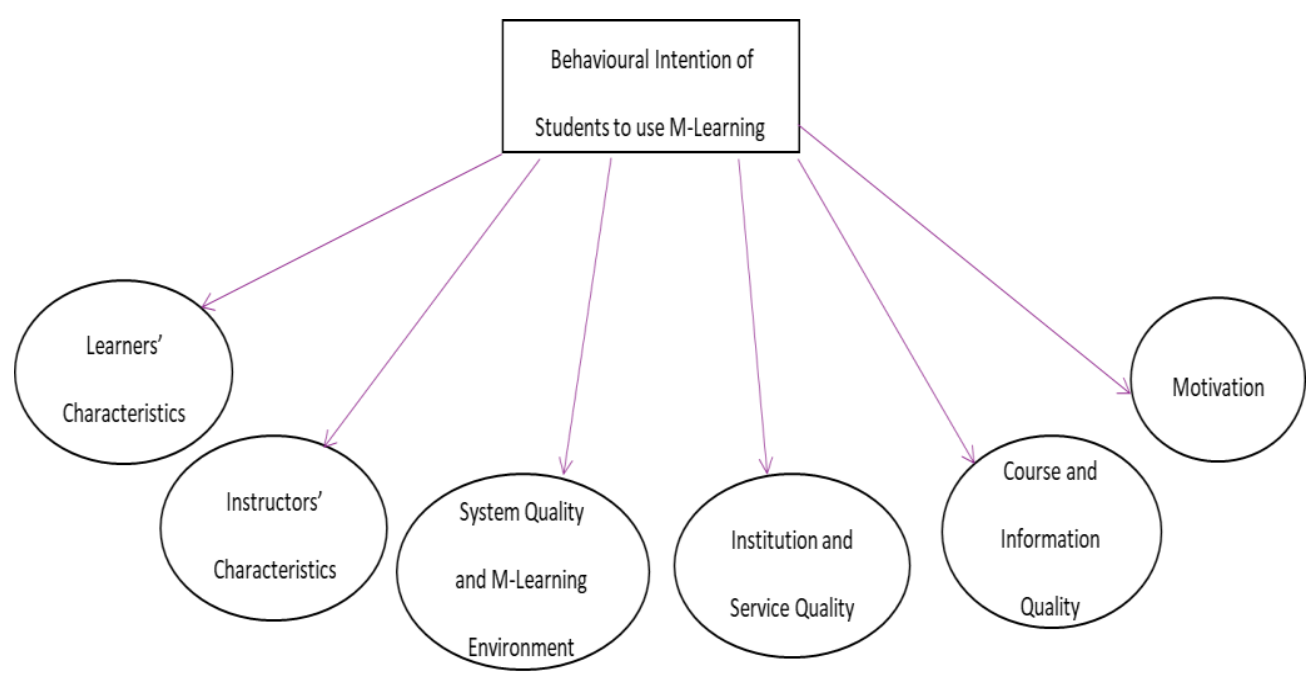

Fig. 1. Dimensions of users' behavioural intention

The first dimension represented 'learners' characteristic' as the main user in M-learning. The second one was 'instructors' characteristics', including perceptions of effectiveness when using e-learning LMS, attitudes towards technology and style of teaching. The third dimension was 'system quality and M-learning environment', which was defined as 'the mobile learning environment performance characteristics as perceived by the stakeholders' [5]. DeLone et al. stated that learners' belief in the effectiveness of E-learning was affected by system quality and how easily it could be accessed via functionality, ease of use, reliability, flexibility, data quality, portability, integration and importance [6]. The fourth dimension represented 'institution and service quality support characteristics' which referred to the holistic support provided by management such as the school administrator. This dimension strongly affected learners' satisfaction. The fifth dimension was 'curriculum and information quality characteristics' that 
included the digital content of the subject as topics and lessons. Information quality represents the required output characteristics of an information system which is, in this case, 'mobile application' [5]. The final dimension was 'motivation' that is either intrinsic or extrinsic. For intrinsic motivation, the person works and performs to their best without any expectations of tangible rewards, while extrinsic motivation refers to the person working for some tangible reward such as money, fame, or a grade [5]. These dimensions and their constituent CSFs are summarised in Table 1. [5] .

Table 1. CSFs affected by dimensions of behavioural intention according to [5].

\begin{tabular}{|l|l|l|}
\hline \multicolumn{1}{|c|}{ Dimension } & \multicolumn{1}{c|}{ CSFs } & \multicolumn{1}{c|}{ Definition of Dimension } \\
\hline $\begin{array}{l}\text { Learners } \\
\text { characteristics }\end{array}$ & $\begin{array}{l}\text {-Computer } \\
\text { self-efficacy } \\
\text {-Internet self- } \\
\text { efficacy } \\
\text {-Computer } \\
\text { and internet } \\
\text { experience } \\
\text {-Computer } \\
\text { anxiety [6] }\end{array}$ & $\begin{array}{l}\text { Diversity of learners in the class } \\
\text { determine the ability of } \\
\text { understanding lessons }\end{array}$ \\
\hline $\begin{array}{l}\text { Instructor } \\
\text { characteristics }\end{array}$ & $\begin{array}{l}\text {-Attitude } \\
\text {-Style in } \\
\text { teaching } \\
\text {-Technology } \\
\text { control }\end{array}$ & $\begin{array}{l}\text { Instructors' perceptions towards } \\
\text { the efficacy of E-learning } \\
\text { management system }\end{array}$ \\
\hline $\begin{array}{l}\text { System quality } \\
\text { \& mobile } \\
\text { learning } \\
\text { environment }\end{array}$ & $\begin{array}{l}\text {-Learner } \\
\text { Adoption to } \\
\text { E-learning } \\
\text {-Learner } \\
\text { belief }\end{array}$ & $\begin{array}{l}\text { The mobile learning environment } \\
\text { performance characteristics as } \\
\text { perceived by the stakeholders }\end{array}$ \\
\hline $\begin{array}{l}\text { Institution \& } \\
\text { service quality }\end{array}$ & $\begin{array}{l}\text {-Learner } \\
\text { satisfaction }\end{array}$ & $\begin{array}{l}\text { The service provided by the } \\
\text { school administrator }\end{array}$ \\
\hline $\begin{array}{l}\text { Curriculum \& } \\
\text { information } \\
\text { quality }\end{array}$ & $\begin{array}{l}\text {-Accuracy } \\
\text {-Timeliness } \\
\text {-consistency } \\
\text {-Relevance to } \\
\text { course }\end{array}$ & $\begin{array}{l}\text { Curriculum: lessons, topics, } \\
\text { content to be digitized into a } \\
\text { mobile learning environment } \\
\text { Information: desired output } \\
\text { characteristics of an information } \\
\text { system is used }\end{array}$ \\
\hline Motivation & $\begin{array}{l}\text {-Intrinsic } \\
\text {-Extrinsic } \\
\text { intrinsic: performance of users } \\
\text { Extrionally or accidentally } \\
\text { activity to get the external prize } \\
\text { such as money, grades, or fame }\end{array}$ \\
\hline
\end{tabular}

Two frameworks were integrated and enveloped into models such as the Technology Acceptance Model (TAM), which is used to assess users' behavioural adoption of technology, and the Information Success Model (ISM), which is used to measure the quality of information systems and course information quality. Some external variables were also included, such as Perceived Ease Of Use (PEOU), which was defined as the extent of the user's perception that 
using a system is free of effort [7], and Perceived Usefulness (PU) that denotes the extent of the user's perception that his/her job performance will be enhanced by using a system [7]. These external variables controlled the users' utilization of technology including belief, attitude, and intention of use. On the other hand, four variables that strongly affected system quality were included such as Learner Satisfaction, Behavioural Intention to use M-learning, Performance Expectation and Perceived Usefulness [5]. Definitions of all dimensionsare have been presented in Table 1 as well as details of what specific CSFs affect each dimension.

\section{Barriers to Adopt E-learning Public Health Sector in South Africa}

Addressing critical success factors (CSFs) was found to have assisted in facilitating the adoption of e-learning in public health care in South Africa, emphasizing the most influential CSF. This study took into consideration social and cultural elements [2]. Some barriers that impeded the implementation of e-learning in South Africa included lack of technical infrastructure, organizational barriers such as insufficient policies and legislations, absence of face-to-face interaction and irrelevant content. Table 2. below demonstrates five CSFs and barriers to adopting e-learning for public health sector students in South Africa.

Table 2. CSFs and related barriers to adopting e-learning according to [2]

\begin{tabular}{|c|c|c|}
\hline & CSFs & $\begin{array}{l}\text { Barriers to adopting e- } \\
\text { learning }\end{array}$ \\
\hline 1 & $\begin{array}{l}\text { Adequate finance for } \\
\text { sustainability }\end{array}$ & $\begin{array}{l}\text {-Finance } \\
\text {-Physical infrastructure } \\
\text {-HR infrastructure }\end{array}$ \\
\hline 2 & $\begin{array}{l}\text { Adequate infrastructure for } \\
\text { sustainability }\end{array}$ & $\begin{array}{l}\text {-Connectivity problems } \\
\text {-Lack Bandwidth } \\
\text {-Hardware \& software } \\
\text { problems }\end{array}$ \\
\hline 3 & $\begin{array}{l}\text { Implementation of policies } \\
\text { and legislations }\end{array}$ & $\begin{array}{l}\text {-Policies \& legislations } \\
\text {-Culture of public health } \\
\text { service }\end{array}$ \\
\hline 4 & $\begin{array}{l}\text { Invest effective change } \\
\text { management facilities }\end{array}$ & $\begin{array}{l}\text { - Policies \& legislations to } \\
\text { move from traditional to e- } \\
\text { learning education } \\
\text {-Irrelevant content } \\
\text {-Culture } \\
\text {-Face-to-face contact }\end{array}$ \\
\hline 5 & $\begin{array}{l}\text { Training for computer } \\
\text { literacy \& E-learning } \\
\text { systems }\end{array}$ & $\begin{array}{l}\text {-HR infrastructure } \\
\text {-Finance } \\
\text {-Culture of public health } \\
\text { service } \\
\text {-Relevant content }\end{array}$ \\
\hline
\end{tabular}

From Table 2, it is noticeable that most barriers fall in the domains of management facilities and training for computer skills. To invest in effective change management and improving facilities, policies and legislations are required to transfer from the traditional learning 
environment to E-learning education. Relevant content of the curriculum should be assigned, besides face-to-face contact during the implementation of E-learning education. Additionally, cultural issues must be borne in mind especially since some societies do not easily adapt to or accept E-learning.

Preparation of efficient human resources and adequate financial support will support training courses for computer literacy and E-learning systems. Furthermore, spreading the importance of health service among the population will change the negative attitudes embedded in the culture.

Addressing such barriers will help the adoption of e-learning in public health care in South Africa. Moreover, the government has an important role to play in this endeavour.

\section{Designing E-learning framework for higher education}

Implementing E-learning within education in Kuwait required developing strategies for enabling universities to engage with the new technology in order to gain rapid, easy, and direct access to the information and knowledge that students required. Once implemented within education, students will able to participate in discussions with their peers and instructors, either within groups or individually. Many universities have embraced the concept of E-learning for higher education and are designing and implementing E-learning frameworks. Consequently, it is important to design a learning management system (LMS) that is fit for purpose and which is usually utilized by instructors. Students can easily access various materials from the LMS, complete their assignments and discuss issues with their peers. They can also utilize the Elearning framework for a more flexible learning process [8].

To transition from traditional learning to E-learning, CSFs should be incorporated into the process to achieve goals as illustrated in Figure 2 [8].

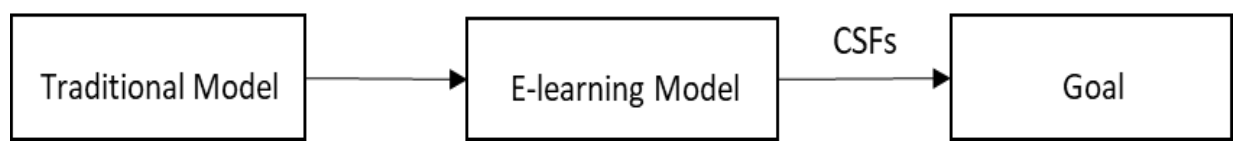

Fig. 2. The transformation from the traditional model to the E-learning model.

Based on 54 journal articles, which have been reviewed and discussed, the following pie chart in Figure 3. illustrates the most frequently reported elements of E-learning for higher education [8] The E-learning LMS/System was the element most frequently reported (26\%) followed by the E-learning activity element (24\%) [8]. 


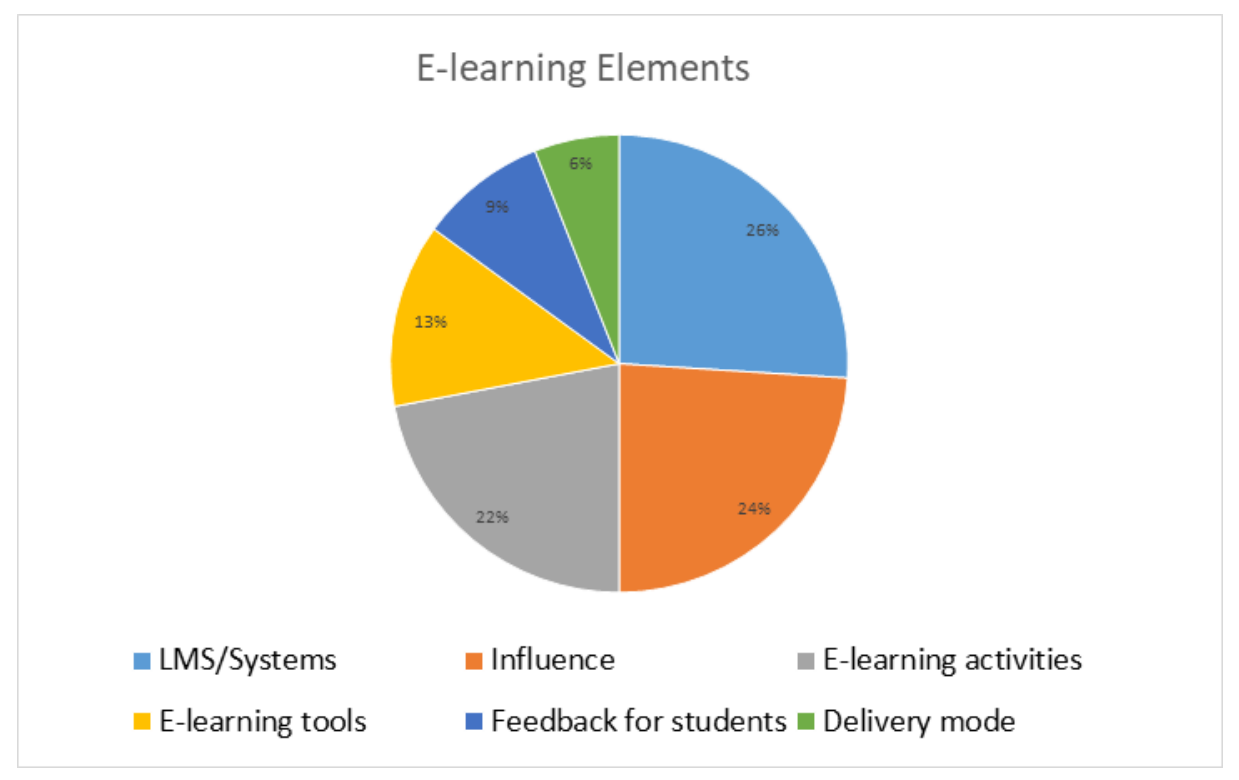

Figure 3. The most frequent-argued E-learning elements.

The results of the review revealed 17 critical success factors that positively affected Elearning in higher education and that the key element in implementing the E-learning as an IT infrastructure was a fit-for-purpose LMS. E-learning tools represented the second critical success factor, followed by E-learning models, then the readiness of the institution, and interaction and learning culture, which had the same percentage frequencies as shown in Table 3. [8].

\section{Smart Schools in Kuwait}

The Kuwait Foundation for the Advancement of Sciences (KFAS) was established and sponsored the Sabah Al-Ahmad Centre for Giftedness and Creativity (SACGC) as a non-profit school. The main purpose of this academy is to support and sponsor smart individuals and encourage them to achieve their own inventions and innovations in order to become globally certified [9]. The academy was equipped with a high-quality IT infrastructure consisting of software and hardware to enable the institution to achieve its mission.

In May 2010, under the recommendation of Prince Sheikh Sabah, the most creative students were selected to be enrolled in this academy in order to encourage them to be more talented and effective in the community after graduation [9]. This new venture commenced with a class that included talented students from public schools located in the following four areas: area 1 was located in AlAsema, area 2 in AlFarwaniya, area 3 in AlJahra, and area 4 in AlAhmady. Because the number of students increased, the government established this academy to gather all talented students in order to sponsor them as creatives. Subsequently, any student who has the desire to enroll in this academy can register for free through the website of the academy by completing 
an online application form. Following this, applicants must pass the talent test after which the administration will take the decision whether the applicant is accepted or rejected [9].

There are some restrictions in this school such as the fact that the curriculum delivered at the academy is in the Arabic language only and also that it only serves grades 7,8 and 9 in all subjects, such as mathematics, chemistry, geology, physics, computer science and biology. On the other hand, the academy supports individuals with science and technology talents as well as craftsmanship professions related to technology [9].

Table 3. The critical success factors of E-learning in higher education according to [8]

\begin{tabular}{|c|l|c|c|}
\hline & \multicolumn{1}{|c|}{ CSF } & Percentage & Priority \\
\hline 1 & Internet Access & $4 \%$ & 7 \\
\hline 2 & E-learning tools & $11 \%$ & 2 \\
\hline 3 & Users' motivation & $5 \%$ & 6 \\
\hline 4 & $\begin{array}{l}\text { Technical competency- } \\
\text { student }\end{array}$ & $6 \%$ & 5 \\
\hline 5 & $\begin{array}{l}\text { Technical competency- } \\
\text { instructor }\end{array}$ & $4 \%$ & $7^{*}$ \\
\hline 6 & Readiness & $9 \%$ & 3 \\
\hline 7 & Blended Learning & $4 \%$ & $7^{*}$ \\
\hline 8 & Interaction & $7 \%$ & 4 \\
\hline 9 & LMS/System & $14 \%$ & 1 \\
\hline 10 & Learning culture & $7 \%$ & $4^{*}$ \\
\hline 11 & User perception & $4 \%$ & $6^{*}$ \\
\hline 12 & E-learning materials & $11 \%$ & $7^{*}$ \\
\hline 13 & E-learning model & $4 \%$ & $2^{*}$ \\
\hline 14 & Training & $1 \%$ & $7^{*}$ \\
\hline 15 & Digital library & $2 \%$ & 9 \\
\hline 16 & Instructional design & $1 \%$ & $9^{*}$ \\
\hline 17 & Critical thinking & & \\
\hline
\end{tabular}

Note, $*$ refers to duplicate values

\section{Results and Discussions}

Many researchers have discussed the most effective CSFs, and they proposed hypotheses, frameworks, and models to predict the appropriate ones to support BL. They found plenty of factors that cannot be standardized for a specific institution because other factors tended to be confounding, such as region, culture, society, etc.

It is important to take advantage of what researchers found in their studies and to test some suitable success factors in the context of Kuwait. It was important to consider cultural aspects when deciding which CSFs of students were to be assessed to raise their outcomes.

The Kuwait Foundation for the Advancement of Sciences (KFAS) did not examine any success factors for their students. Their evaluation depended on the scores gained before admission to the academy. However, it is important to identify success factors through academic 
research in order to specify the effective success factors that are applicable to Kuwait as an Arabic region.

Based on 61 previous studies, CSFs have been assembled in addition to sub-factors in order to propose a diagram as shown below in Figure 4. This diagram was used to select CSFs and to measure them in terms of whether they enhanced the level of students to reach the goal, or to select another CSF and to test them again until the most effective CSFs were identified that were applicable to students in high schools in Kuwait.

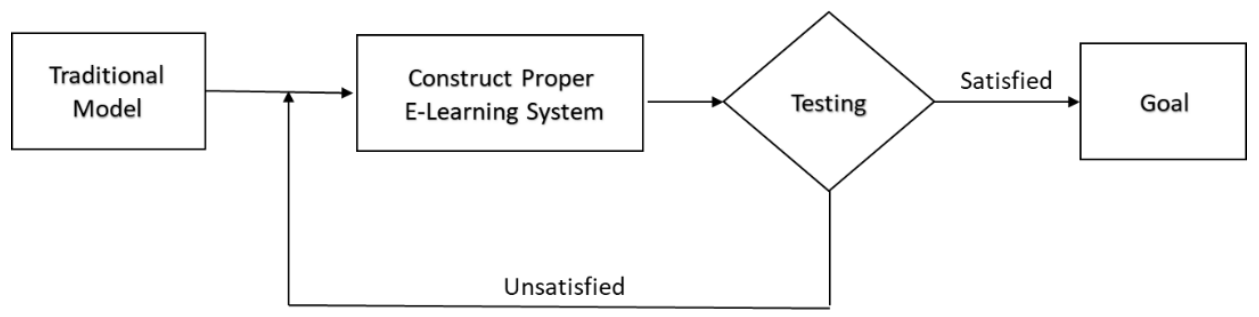

Fig. 4. To transfer from a traditional model to E-learning model using CSFs

\section{Conclusions}

Examining effective success factors requires navigation through several studies to collect plenty of CSFs and to test them. This will assist us to find the appropriate ones to be implemented in Kuwait taking into account the culture, region, and social standards.

We conclude that the most effective CSFs that institutions need to achieve the highest rate of success is 'Technology' with all its similar applications or components. Such components include technology control [10], E-learning system development [10], technologies [10], training for computer literacy \& E-learning systems [11], system quality [12], E-learning LMS/system, internet access, E-learning tools, blended learning, LMS/system, E-learning materials and E-learning model [8]. In addition to these are sub-factors, which are related to technology, followed by skills and competencies for using technology for both students and instructors.

Proper preparation of IT infrastructures such as software and hardware will contribute to strengthening users' competencies and skills. Besides this, assigning training courses to use new functions and features that the system support is mandatory in order to cope with recently released versions of the system's facilities. Furthermore, BL was found to be one of the critical success factors [8]. Nevertheless, more studies are needed to classify CSFs taking into consideration some characteristics such as region, culture, and individual perspectives.

For Kuwait, IT infrastructure is available including software and hardware. However, the researches into CSFs are absent. Thus, conducting research to find the most effective CSFs is demanded in order that talented high school students are facilitated to attain the highest levels of success. 


\section{References}

[1] Ismail Salaheldin, S., Critical success factors for TQM implementation and their impact on performance of SMEs. International journal of productivity and performance management, 2009. 58(3): p. 215-237.

[2] Gcora, N. and L. Cilliers. Critical success factors for eLearning adoption in the public health care sector in South Africa. in 2016 IST-Africa Week Conference. 2016. IEEE.

[3] Ingram, H., et al., Internalizing action learning: a company perspective. Establishing critical success factors for action learning courses. International Journal of Contemporary Hospitality Management, 2000. 12(2): p. 107-114.

[4] Alkarney, W. and M. Albraithen. Critical Success Factors for Learning Management System Implementation: Non-Scientific Colleges Case A Conceptual Model. in 2018 21st Saudi Computer Society National Computer Conference (NCC). 2018. IEEE.

[5] Fabito, B.S. Exploring Critical Success Factors of Mobile Learning as Perceived by Students of the College of Computer Studies-National University. in 2017 International Conference on Soft Computing, Intelligent System and Information Technology (ICSIIT). 2017. IEEE.

[6] Bhuasiri, W., et al., Critical success factors for e-learning in developing countries: A comparative analysis between ICT experts and faculty. Computers \& Education, 2012. 58(2): p. 843-855.

[7] Abdullah, F. and R. Ward, Developing a General Extended Technology Acceptance Model for E-Learning (GETAMEL) by analysing commonly used external factors. Computers in Human Behavior, 2016. 56: p. 238-256.

[8] Asalla, L.K., M.R. Putri, and Y.D. Pradipto. The critical success factor of E-learning in higher education: A systematic literature review, IEEE International Conference on Information Management and Technology (ICIMTech), 15-17 November 2017, Melia Purosani Hotel, Yogyakarta, Indonesia, pp. 192-197.

[9] Creativity, S.A.A.C.f.G.a. Scientific Application Workshops. 2019 [cited 2019 November 2019]; Available from: https://www.sacgc.org/.

[10] Anggrainingsih, R., et al. Determining elearning critical success factor at sebelas maret university using Analytical Hierarchy Process (AHP), IEEE International Seminar on Application for Technology of Information and Communication (ISemantic), 2016, pp. 192-196.

[11]Davis, F.D., A technology acceptance model for empirically testing new end-user information systems: Theory and results. 1985.

[12] Yassine, S., M. Khalifa, and P. Franck. Towards a multidimensional model to study a critical success factors affecting continuity and success in e-learning systems, 10th IEEE International Conference on Developments in eSystems Engineering (DeSE), 2017, pp. 129-134. 